\title{
Completely Aqueous Procedure for Growth of Polymer Brushes on Polymeric Substrates
}

Parul Jain, Jinhua Dai, Sebastian Grajales, Sampa Saha, Gregory L. Baker, and Merlin L. Bruening

Department of Chemistry, Michigan State University, East Lansing, Michigan 48824

\section{Supporting Information.}

Synthesis of 2-(2-bromoisobutyryloxy)ethyl acrylate (BIEA). 2-Hydroxyethyl acrylate (11.6 $\mathrm{g}, 0.1 \mathrm{~mol})$ and triethylamine $(11.2 \mathrm{~g}, 0.11 \mathrm{~mol})$, dried over 4-Å molecular sieves, were dissolved in dry dichloromethane $(150 \mathrm{~mL})$. The mixture was cooled in an ice bath, and a $15 \mathrm{~mL}$ solution of $\alpha$-bromoisobutyryl bromide ( $24 \mathrm{~g}, 0.10 \mathrm{~mol}$ ) in dry dichloromethane was added drop-wise. After the addition was complete, the ice bath was removed, and the reaction mixture was stirred at room temperature for $3 \mathrm{~h}$. The solution was filtered to remove triethylammonium bromide and the salt was washed with dichloromethane $(100 \mathrm{~mL})$. The organic solutions were combined and washed sequentially with $250 \mathrm{~mL}$ of $0.1 \mathrm{M} \mathrm{HCl}, 250 \mathrm{~mL}$ saturated $\mathrm{NaHCO}_{3}$, and $250 \mathrm{~mL}$ water. After drying the organic phase over anhydrous $\mathrm{Na}_{2} \mathrm{SO}_{4}$, the solvent was removed in vacuum to provide $24.2 \mathrm{~g}$ of BIEA in $92 \%$ yield. ${ }^{1} \mathrm{H} \mathrm{NMR}\left(\mathrm{CDCl}_{3}\right): \delta 6.41(\mathrm{dd}, J=18 \mathrm{~Hz}, J=2.2 \mathrm{~Hz}, 1 \mathrm{H})$, 6.11 (dd, $J=18 \mathrm{~Hz}, J=18 \mathrm{~Hz}, 1 \mathrm{H}$ ), 5.84 (dd, $J=11 \mathrm{~Hz}, J=2.2 \mathrm{~Hz}, 1 \mathrm{H}$ ), 4.40 (s, 4H), 1.90 (s, $6 \mathrm{H})$.

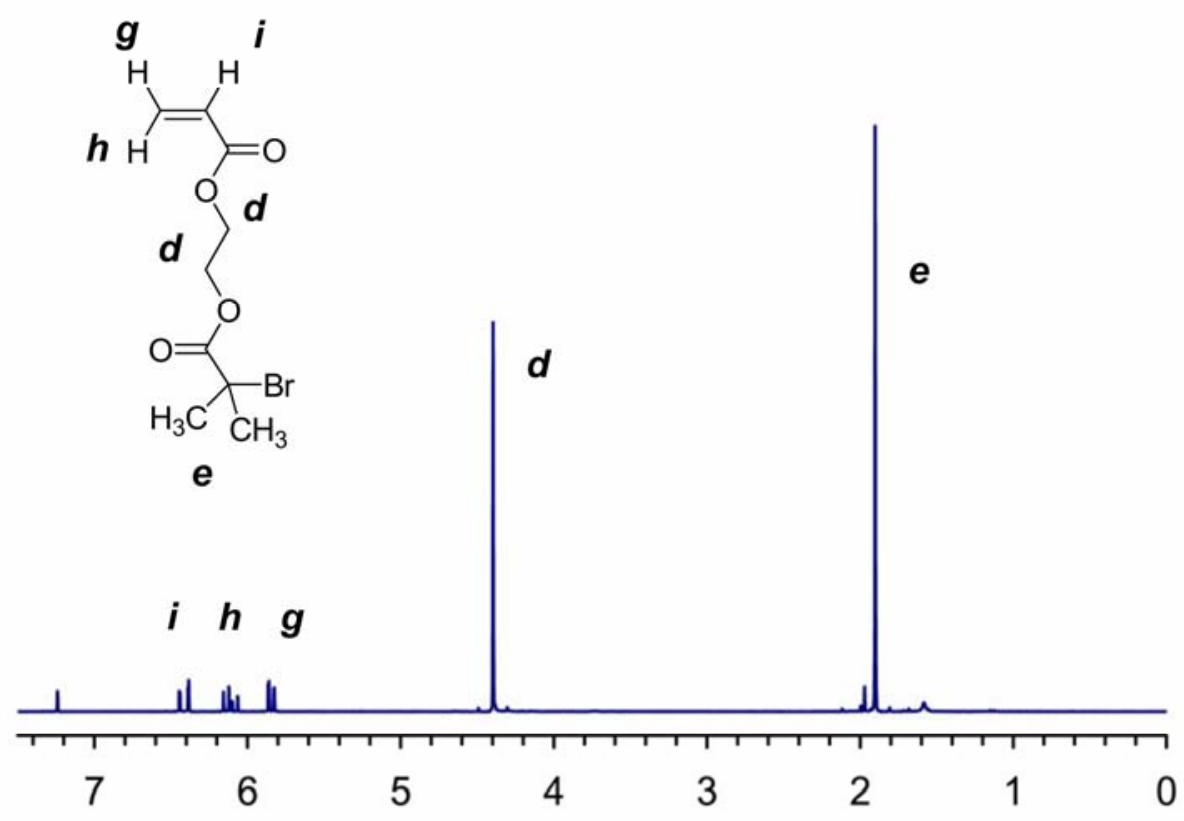

Figure SI-1. ${ }^{1} \mathrm{H}$ NMR (300 MHz, $\mathrm{CDCl}_{3}$ ) of 2-(2-bromoisobutyryloxy)ethyl acrylate (BIEA). 
Determination of the internal surface area of a PES membrane. 15 Pieces of polyethersulfone membranes $\left(255 \mathrm{mg}\right.$ ) were degassed for $48 \mathrm{hrs}$ at $80{ }^{\circ} \mathrm{C}$ and $10^{-6}$ torr prior to analysis. The instrument used to obtain the $\mathrm{N}_{2}$ adsorption/desorption isotherms was a Micromeritics ASAP 2010 Sorptometer using static adsorption procedures at $-196{ }^{\circ} \mathrm{C}$. The BET surface area was calculated to be $1800 \mathrm{~cm}^{2} /$ membrane from the linear part of the BET plot according to IUPAC recommendations. ${ }^{1}$
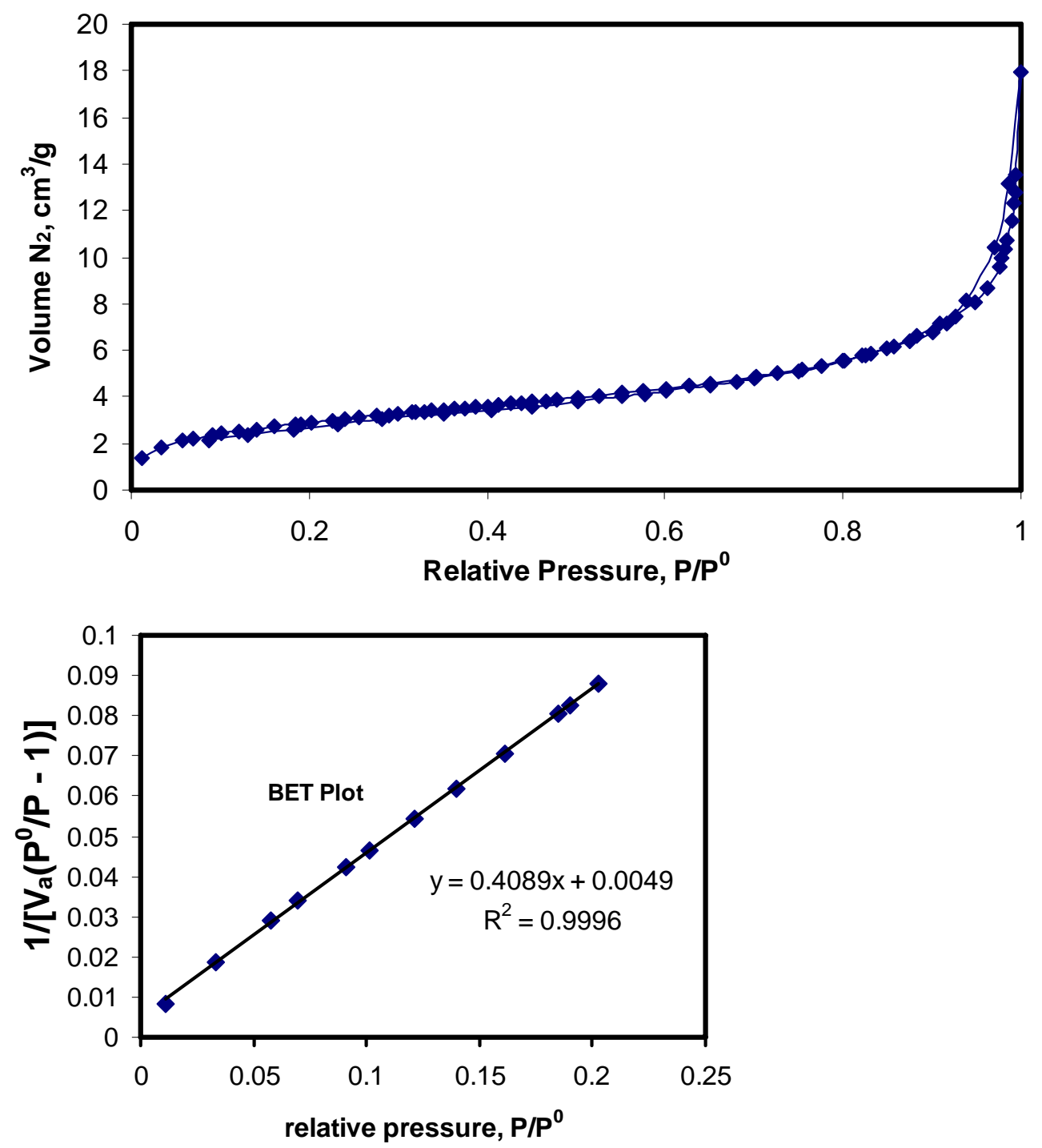

Figure SI-2. Top: The nitrogen adsorption/desorption isotherm for PES membranes. $\mathrm{P}^{0}$ is the nitrogen vapor pressure. Bottom: BET plot between relative pressures of 0.01 and 0.2 , where $V_{a}$ is the volume of gas adsorbed. The slope and y-intercept of the best fitting line were used to determine the BET surface area.

${ }^{1}$ Sing, K.S.W; Everett, D.H.; Haul, R.A.W.; Moscou, L.; Pierrotti, R.A.; Rouquerol, J.; Siemieniewski, T. Pure Appl. Chem. 1985, 57, 603. 


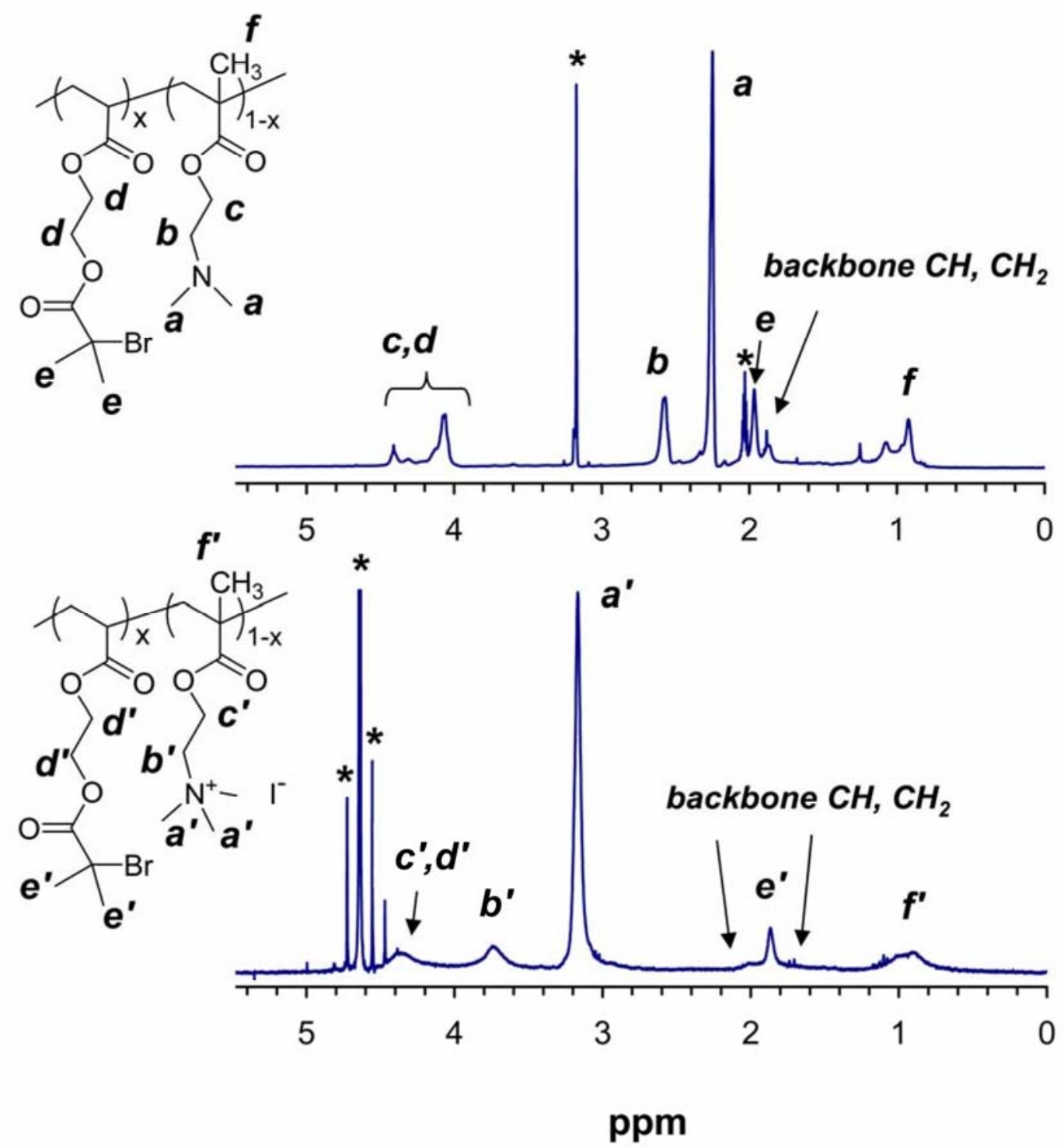

Figure SI-3. ${ }^{1} \mathrm{H}$ NMR spectra of poly(DMAEMA-co-BIEA) (top, acetone- $d_{6}+$ trace $\mathrm{D}_{2} \mathrm{O}$ as solvent) and its quaternized product poly(TMAEMA-co-BIEA) (bottom, $\mathrm{D}_{2} \mathrm{O}$ as solvent). The corresponding structures and proton assignments are given in the figure. $*$ indicates resonances from solvents. 


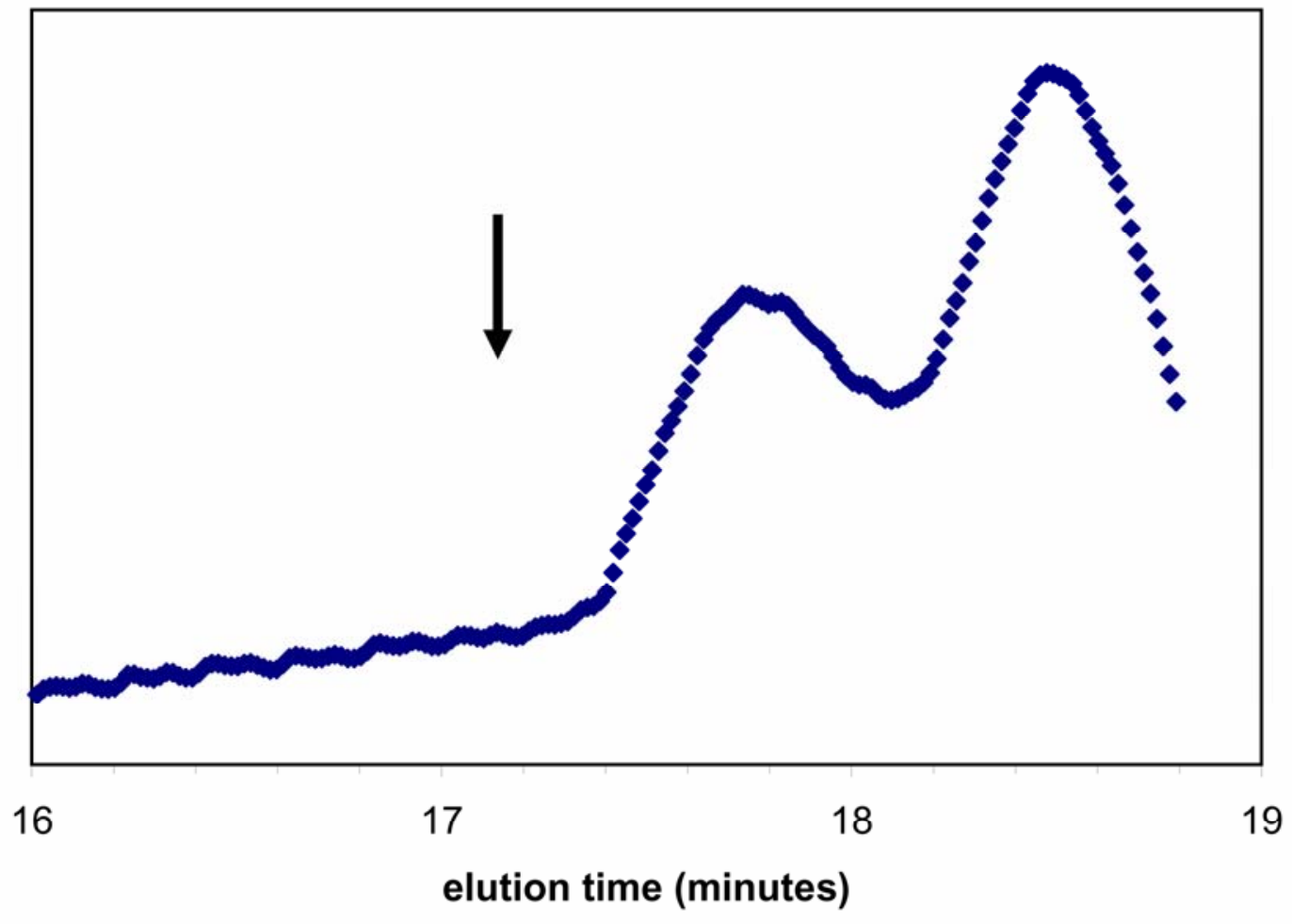

Figure SI-4. GPC trace of poly(TMAEMA-co-BIEA). The sample was run at $35^{\circ} \mathrm{C}$ using two PL gel $10 \mathrm{~mm}$ mixed-B columns in series, and THF as the eluting solvent at a flow rate of 1 $\mathrm{mL} / \mathrm{min}$. The samples were filtered through a $0.2 \mu \mathrm{m}$ Whatman PTFE syringe filter prior to GPC analysis. The arrow indicates the elution time for the lowest polystyrene standard (2727 $\mathrm{g} / \mathrm{mol}$ ) used for calibrating the columns. The elution time for pure solvent is $\sim 20$ minutes. 


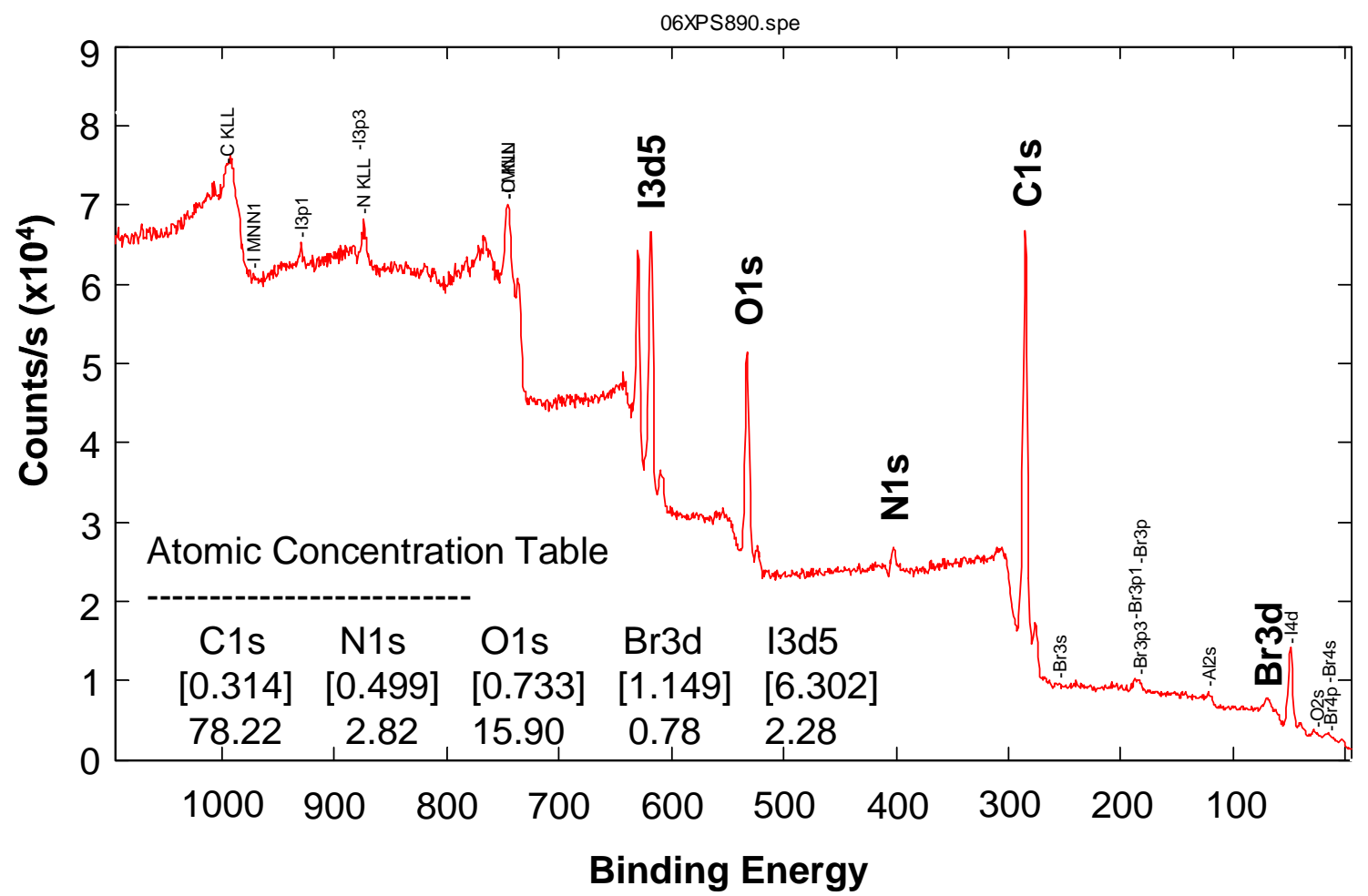

Figure SI-5. XPS elemental analysis of quaternized poly(DMAEMA-co-BIEA). 


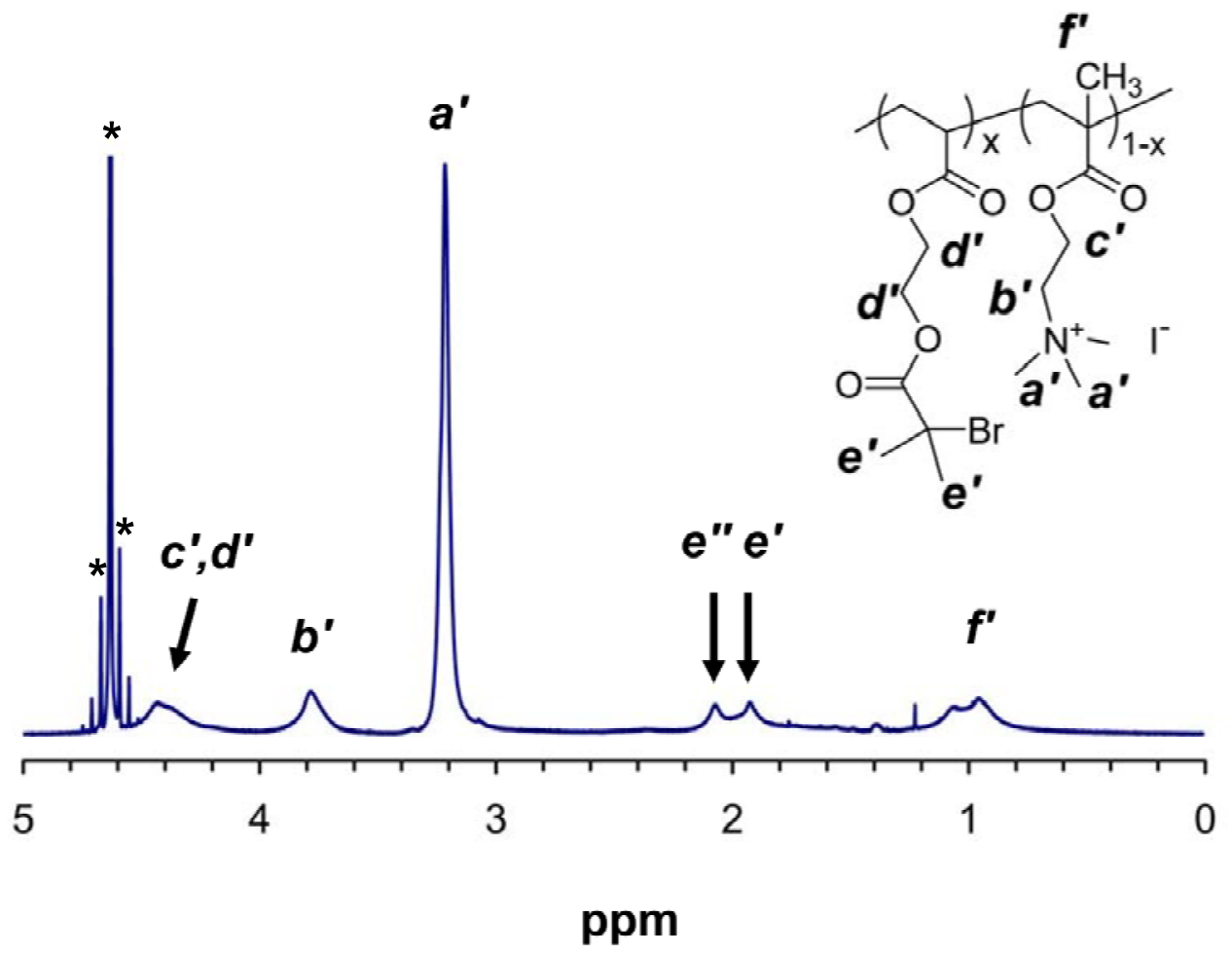

Figure SI-6. ${ }^{1} \mathrm{H}$ NMR spectrum of a 10-month old sample of poly(TMAEMA-Co-BIEA) $\left(\mathrm{D}_{2} \mathrm{O}\right.$ as solvent), showing evolution of the $\alpha$-methyl resonances (e', e') . The corresponding structures and proton assignments are given in the figure. $*$ indicates resonances from solvents. 


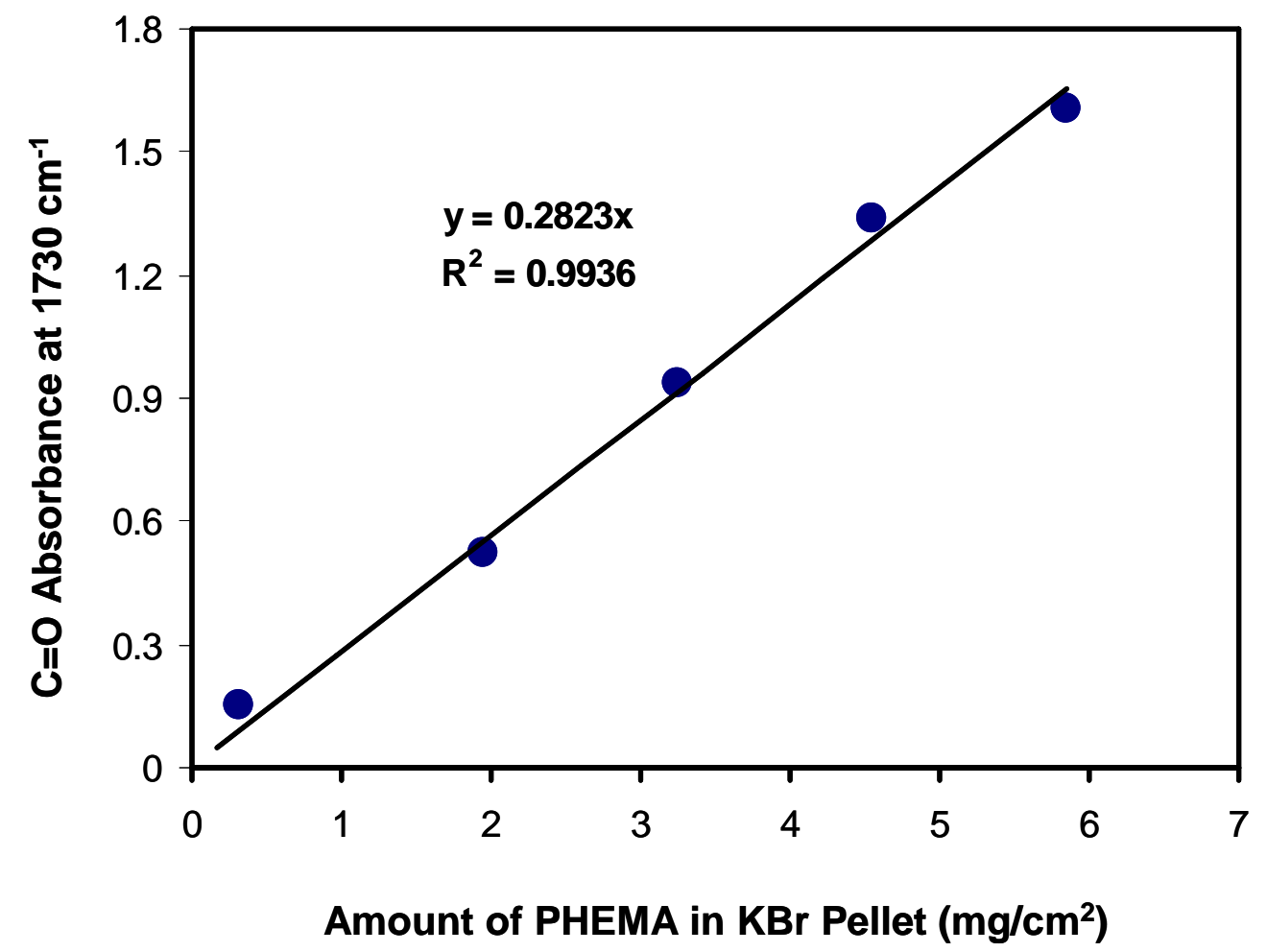

Figure SI-7. Calibration curve of the absorbance at $1730 \mathrm{~cm}^{-1}$ (attributed to the ester carbonyl of PHEMA) versus the areal concentration of PHEMA in $\mathrm{KBr}$ pellets. PHEMA KBr pellets were prepared by thoroughly mixing different amounts of PHEMA and $\mathrm{KBr}$ (the total amount of the mixture was $100 \mathrm{mg}$, and the face of the pellet had an area of $1.54 \mathrm{~cm}^{2}$ ). 